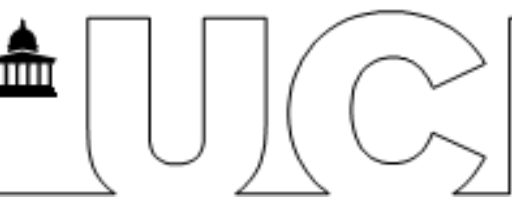

Gardner, S; (2016) Kant's Third Critique: The Project of Unification. Philosophy (In press) Downloaded from UCL Discovery: http://discovery.ucl.ac.uk/ 1471819

\title{
ARTICLE
}

\section{Kant's Third Critique: The Project of Unification}

\author{
Sebastian Gardner \\ Department of Philosophy, University College London
}

\begin{abstract}
This paper offers a synoptic view of Kant's Critique of the Power of Judgement and its reception by the German Idealists. I begin by sketching Kant's conception of how its several parts fit together, and emphasize the way in which the specifically moral motivation of Kant's project of unification of Freedom and Nature distances it from our contemporary philosophical concerns. For the German Idealists, by contrast, the CPJ's conception of the opposition of Freedom and Nature as defining the overarching task of philosophy provides a warrant and basis for bold speculative programmes. The German Idealist development therefore presupposes Kant's failure in the CPJ to resolve the problem of the relation of Freedom and Nature. What is fundamentally at issue in the argument between Kant and his successors is the question of the correct conception of philosophical systematicity and in this context I reconstruct Kant's defence of his claim to philosophical finality.
\end{abstract}

It is fair to say that the third and last of Kant's critiques, the Critique of the Power of Judgement (CPJ), does not hold the same importance for us as its predecessors. The Critique of Pure Reason addresses what are still central concerns of epistemology, metaphysics, and philosophy of mind. The Critique of Practical Reason, paired with the Groundwork, articulates a position that every contemporary moral (and political) philosopher regards as worth engaging with and that some regard as deeply right about fundamental matters. The Third Critique is not in the same league. The difficulties begin when we try to say what it is a critique of. If the title is to be believed, the subject is Urteilskraft, the power of judgement, but judgement as such is discussed only in the Introduction and is in any case for us a topic in philosophical logic, which is certainly not Kant's concern here, while the notion of a 'power' or 'faculty' of judgement does not resonate with our concerns. Only one of the topics treated in the book, the aesthetic, has a relatively firm (though hardly central) place on our contemporary philosophical agenda, and the bulk of the attention paid to the Third Critique is accordingly directed at the first of its two parts, the 'Critique of Aesthetic Judgement', which is standardly taken in isolation from its surroundings. The second part, the 'Critique of Teleological Judgement', centres on a problem that is widely supposed to have been overtaken by Darwin, while the other bits and pieces contained in the work - a few brief sections on the methodology and presuppositions of the natural sciences, some passages on the philosophy of history, a lengthy restatement of Kant's moral theology, and a 
rather strange new account of what defines human cognition -: all of these do not obviously belong to a single train of thought. All in all, then, it can seem that the Third Critique is something of a dog's dinner, and that, once Kant's aesthetics have been liberated from their textual cage and the remainder of the work has been picked over, its interest is exhausted.

There is, I think, not much to be gained by directly contesting this assessment of what the Third Critique has to offer philosophical enquiry of the present day. The worthwhile issue to pursue is instead how and why Kant conceived the work as an integral whole. The first half of my discussion provides accordingly an overview of how its parts are integrated. The second half is devoted to its reception by the German Idealists. This is not a change of subject, for as I hope to show, their critical appraisal raises a deep and difficult question about what, in Kant's terms, constitutes an integral whole of philosophical knowledge. Since this paper is in the nature of a synopsis, the issues on which I touch receive only extremely sketchy treatment, though I try to give a sense of their great complexity. ${ }^{1}$ Although my discussion is not designed to save the philosophical interest of the Critique of the Power of Judgement by showing that its problems are those that form our contemporary agenda, it does not follow that its interest is 'merely' historical: the present case is one in which the history of philosophy best serves philosophical interest by displaying its object's historical distance, showing us a road not taken, or more accurately, a road once taken but later abandoned and now hard to reimagine, but which, when reimagined, reveals a world of possibilities. $^{2}$

\section{Kant's aims in the Third Critique: the project of unification}

If we want to know what in Kant's eyes holds all of its disparate topics together and makes the Third Critique more than a collection of appendices to his Critical system, then we need to look at the Introduction to the work, where we find Kant explaining its unitary project in different ways.

The Introduction is an exercise in architectonic, which Kant defines as the 'art of system', die Kunst der Systeme, where 'system' means an intellectual structure that employs Ideas to transform an aggregate of common cognitions into scientific knowledge, Wissenschaft, a genuine unity. ${ }^{3}$ The key to the architectonic of the $C P J$, as set forth in the Introduction, is not the concept of judgement as such but the idea that the faculty of judgement, which intermediates between our other two conceptual faculties, reason and understanding, has a

\footnotetext{
${ }^{1}$ The complexities are explored in the following recent works, selected because they to a greater or lesser extent address the Critique of the Power of Judgement as a whole: Henry Allison, Kant's Theory of Taste: A Reading of the Critique of Aesthetic Judgment (Cambridge: CUP, 2001), Hannah Ginsborg, The Normativity of Nature: Essays on Kant's Critique of Judgement (Oxford: OUP, 2015), Paul Guyer, Kant's System of Nature and Freedom: Selected Essays (Cambridge: CUP, 2005), Angelica Nuzzo, Kant and the Unity of Reason (Lafayette, IN: Purdue University Press, 2004), Robert Wicks, Routledge Philosophy Guidebook to Kant on Judgement (London: Routledge, 2006), and Rachel Zuckert, Kant on Beauty and Biology: An Interpretation of the Critique of Judgment (Cambridge: CUP, 2007).

${ }^{2}$ Yitzhak Y. Melamed puts the point well in 'Charitable Interpretations and the Political Domestrication of Spinoza, or, Benedict in the Land of Secular Imagination', in Mogens Lærke, Justin E. H. Smith, and Eric Schliesser (eds), Philosophy and Its History: Aims and Methods in the Study of Early Modern Philosophy (Oxford: OUP, 2013), 258-277: 'We should engage in the study of good past philosophers, not in spite, but because of the fact that frequently past philosophers argue for views that are significantly different from ours' (274).

${ }^{3}$ Critique of Pure Reason (henceforth CPR), A832-835/B860-863; see also A13/B27. Determination of form by an Idea is what distinguishes architectonic from merely 'technical' unity.
} 
subterranean connection with the hedonic faculty, the faculty of pleasure and unpleasure, which intermediates between our theoretical and practical powers. The connections are shown in the map of our faculties with which Kant concludes the Introduction: ${ }^{4}$

\begin{tabular}{|c|c|c|c|}
\hline $\begin{array}{l}\text { All the } \\
\text { faculties } \\
\text { of the mind }\end{array}$ & $\begin{array}{l}\text { Faculty of } \\
\text { cognition }\end{array}$ & $\begin{array}{l}\text { A priori } \\
\text { principles }\end{array}$ & Application to \\
\hline $\begin{array}{l}\text { Faculty of } \\
\text { cognition }\end{array}$ & Understanding & Lawfulness & Nature \\
\hline $\begin{array}{l}\text { Feeling of } \\
\text { pleasure and } \\
\text { displeasure }\end{array}$ & $\begin{array}{l}\text { Power of } \\
\text { judgment }\end{array}$ & Purposiveness & Art \\
\hline $\begin{array}{l}\text { Faculty of } \\
\text { desire }\end{array}$ & Reason & Final end & Freedom \\
\hline
\end{tabular}

The guiding idea, then, is that the triadic division of the mind as a whole, the left-hand column, is reproduced within its first term, the faculty of cognition, yielding the second column, each member of which determines, according to its own a priori principle, a specific range of objects. 'Art', the middle term of the last column, refers not just to fine art but primarily to 'nature as art', that is, nature regarded as a technique, i.e. considered teleologically. The importance of this will emerge shortly.

A crucial part of Kant's story is that judgement divides into two classes, what he calls 'determinant' and 'reflective' judgement, distinguished by the way in which they connect particulars and universals. ${ }^{5}$ Determinant judgement subsumes a particular encountered in cognition under a concept which is already given. Reflective judgement seeks out for particulars a concept which is not already given, that is, it seeks to form new concepts. Determinant judgements, theoretical and practical, have already been dealt with in the earlier Critiques. Explicating reflective judgement is the new task, and Kant tells us that the concept-seeking function of judgement is associated with the concept of end or purpose, Zweck; some reflective judgements employ this concept explicitly, predicating it of their objects, and those that do not nonetheless presuppose it in their background. Kant's claim is that, armed with this apparatus, we can substantiate this model of our rational powers, and the main body of the Third Critique is an attempt to supply the detail and fill it out.

It is safe to say that the architectonic project is unlikely to grab us, and while we may look with favour and interest on Kant's endeavour to extend his account of how experience is conceptualized - the new theory of reflective judgement - it may reasonably be doubted that it strictly requires Kant's architectonic surroundings. But Kant has another way of explaining the task of the Third Critique, which makes it seem considerably more inviting. Kant focusses on the needs of the moral agent, who has (he now concedes) been left adrift by the two earlier Critiques, in so far as each of these has merely sought to account for its own domain, without coordinating them. The first Critique established that practical reason's legislation over the 'domain' (Gebiet) of Freedom, and theoretical reason's legislation over Nature, cannot conflict, even though their 'territory' (Boden) is the same, namely objects of

\footnotetext{
${ }^{4}$ Critique of the Power of Judgement (henceforth $C P J$, followed by the Akademie Ausgabe pagination), ed. Paul Guyer, trans. Paul Guyer and Eric Matthews (Cambridge: CUP, 2000), Introduction, Sect. IX, 5:198.

${ }^{5}$ The new conception of reflective judgement is needed in order to give substance to the idea that judgement constitutes a distinctive faculty of its own; without it, Kant would have little reason to add to the brief remarks on the power of judgement in the Critique of Pure Reason (A132-136/B171-175).
} 
possible experience; and the second Critique showed what use can be made of the concept of Freedom, once it has been rendered unproblematic. But this separation has not been followed up by any reunification. Here is the famous paragraph stating the problem:

Now although there is an incalculable gulf [eine unübersehbare Kluft] fixed between the domain of the concept of nature, as the sensible, and the domain of the concept of freedom, as the supersensible, so that from the former to the latter (thus by means of the theoretical use of reason) no transition is possible, just as if there were so many different worlds, the first of which can have no influence on the second: yet the latter should have an influence on the former [...] Thus there must still be a ground of the unity of the supersensible that grounds nature with that which the concept of freedom contains practically, the concept of which, even if it does not suffice for cognition of it either theoretically or practically, and thus has no proper domain of its own [kein eigentümliches Gebiet hat], nevertheless makes possible the transition from the manner of thinking [Übergang von der Denkungsart] in accordance with the principles of the one to that in accordance with the principles of the other. ${ }^{6}$

Now this talk of unifying Freedom and Nature brings to mind a very familiar task, the problem of understanding the relation of the mental to the physical and of normativity to nature. What one makes of those dualities - whether one affirms the reality of mind and normativity, and if so in what form - is decisive for the particular form of naturalism, if any, that one regards as defensible. This might seem to make the Critique of the Power of Judgement a book for our times, but there are deep differences between Kant's conception of the task of unification, and the tasks that occupy us, which once again set the Third Critique at a historical distance.

First, Kant denies that a unification of the physical and the mental, of the kind we consider necessary if substance dualism is to be avoided, is possible: the first Critique argues that transcendental idealism, which interrelates the physical and the mental systematically at the level of our representations of each and denies them any further knowable essence, provides the only coherent account of the mind-body relation; on Kant's view, it is only if we mistake inner and outer appearances for things in themselves that we will we attempt to determine their underlying metaphysical relation.

Second, and even more importantly, Kant's task of unification has the specific presupposition that 'Freedom' has at its core what Kant calls pure practical reason, that is, the moral law. If practical reason were exclusively empirical, then its integration with theoretical reason would present no problem: practical reason would already be integrated with nature, since its job would simply be to steer action in accordance with the inclinations that nature has given us.

There is scope for different interpretations of the exact problem to which Kant is drawing attention in this passage, but from what he says later in the main body of the text, it would appear that he is concerned with the success conditions of the worldly moral enterprise. In order to act morally, I need to believe that my actions qua moral stand a chance of success, and no reassurance on this front is supplied by my long experience of getting my body to move when I want it to, and of succeeding in a reasonable number of morally indifferent

\footnotetext{
${ }^{6} \mathrm{CPJ}$, Introduction, Sect. II, 5:175-176.
} 
tasks. These successes tell me only that I qua natural creature fit well enough into the natural world. Whether I also do so as a moral being is another matter.

This problem of a need for moral reassurance differs from the one that Kant addressed in the Dialectic of the second Critique, and which he claimed to solve there by means of the theological postulates. There, the problem concerned the non-identity of morality and happiness, which threatened to check moral willing at its root: the worry was that, if to form a dutiful will is to renounce the hope of, to declare oneself indifferent to, happiness, then the demands of morality are nonsensical for creatures like us, who have compound rational-andsensible natures. Here in the Third Critique the problem is that, even if I am reassured by Kant's moral theology that morality and happiness harmonize ultimately, outside the natural world if not within it, still I have no reason to think that the world is going to prove receptive to my moral purposes - that it is the sort of world in which it makes sense to act morally. The problem may express itself in concrete worries about the seeming futility of striving for, say, a just society in face of global capitalism, but ultimately it consists in a hiatus at the intersection of theoretical and practical reason: the problem is that no content has yet been given to the thought that the natural world - the world that we know - and the moral world the world that we will - are the same world. Still less do we have grounds for thinking of them as congruent. Of course we can frame thoughts in which elements from each world are adjoined - I can think that this empirical object is something that I have borrowed and thus ought to return - and these thoughts can effectively determine me to act, but how all this is possible is left a mystery. ${ }^{7}$

In sum, then, because Kant's specific problem of unifying Freedom and Nature presupposes his identification of Freedom with morality conceived as pure practical reason, and because Kant's resolution of this problem is not going to help with the mind-body problem that we have resumed from the early moderns, it continues to seem that there is little reason to expect the Third Critique to engage with our concerns. And if we turn to the detail of its argument, we find this suspicion largely confirmed.

The argument of the CPJ starts with Kant's analysis of judgements of taste, which is guided by the assumption that these must be differentiated sharply from moral judgements on the one side and judgements of the mere 'agreeable' on the other. As Kant's analysis unfolds, we learn that aesthetic response arises from a special configuration of our ordinary cognitive faculties, and it is demonstrated that beautiful objects manifest the transcendental fact that nature is mind-congenial in a way that goes beyond the conformity of nature to our understanding argued in the first Critique: we do not prescribe to the rose its specific form, on account of which its bare disinterested apprehension brings pleasure; the rose did not need to give pleasure, in order to be knowable, but it does so nevertheless; what it does for us is an epistemological supererogation. This deepens the sense in which mind and nature cohere - it exposes another, deeper level at which our theoretical power and nature are fitted to one another - but it is not enough to effect a rapprochement of Freedom and Nature. For that, Kant needs to show that, despite the sharp distinction of aesthetic from moral judgements, there is a point where the two come together. And so Kant extends his analysis in an attempt to show that the 'rightness' to which judgements of beauty lay claim - the

\footnotetext{
${ }^{7}$ An analogy may be drawn with the problem of the Transcendental Deduction concerning how appearance can be conformable to the categories.
} 
rose's normative halo, its 'calling for' pleasure to be taken in it, and our calling, in our judgement, for others to take pleasure in it - can be accounted for only if we have in view, albeit in a very indefinite and indirect way, the moral good. As Kant puts it, the beautiful is a 'symbol of morality', and taste is a power of estimating the way in which moral ideas have been rendered sensible.

Kant's theory of the sublime, the junior partner of his theory of beauty, reaches the same general result - insight into the moral meaningfulness of aesthetic response - through a more circuitous route, and in a way that supplements the moral vision of beauty. With beauty, the moral good as it were shines through the natural object: the rose is at one with its morally purposive ground. In the case of the sublime - the towering mountain and the raging storm - the face that nature displays is indifferent or hostile. But because this extinction of our empirical significance (the mountain and storm brushing us aside as mere perishable specks) induces awareness of our essential transcendence of nature (no mere natural phenomenon can touch what we essentially are), the sublime teaches that the counter-purposivity found at the surface of Nature is in the service of an underlying moral purposiveness. The harsh lesson of sublime nature is that we can, after all, consider ourselves imperishable, but only on the condition that we are prepared to sacrifice our natural existence, should the moral law demand it. The sublime thus reveals our moral fitness, while the beautiful reassures us that, if we are morally adequate, then no actual and uncompensated sacrifice will be required of us. ${ }^{8}$

The second half of the work, the Critique of Teleological Judgement, begins afresh, with another class of distinctive forms encountered in nature, natural organisms, and argues that these demand for their explanation (and even their identification) the concept of a whole which determines its parts. Here the reflective power of judgement is manifested: because the plant or animal exhibits a form that made no sense in mechanistic terms, we had to go looking for a concept under which to bring it. To conceive an object as a living organized being, Kant argues, is to think of the concept of the whole as producing its parts; and since the production by concepts of objects which satisfy those concepts counts for us as purposive rational agency, Kant tells us that natural organisms must be conceived as 'natural ends'. This then sets a double problem, since teleological judgement, though it is judgement of the very same objects that we think via the categories and in accordance with the mechanical principle of causality, is not licensed by the Critique of Pure Reason, in fact it appears to stand in competition with the mechanical forms of explanation that the earlier Critique showed to be strictly necessary.

Kant's solution is to admit teleology on the basis of a strictly regulative construal of its status. This allows him to present teleological judgement as (first) the result of conjoining our need to understand organic form in nature with the form of our faculty of reason, which hankers after wholes or totalities - thereby accounting for the basis of teleological judgements of nature; and (second) as having merely 'as if' force, that is, as entailing nothing whatever regarding the intrinsic constitution of objects, but instead as instructing us how we do best to think about them - thereby eliminating the threat of conflict with mechanism. Once again, then, Kant has enlarged the scope of theoretical reason, but more needs to be provided if the teleologically enriched theoretical picture of Nature is to be joined up with Freedom; on

\footnotetext{
${ }^{8}$ Jointly comprising an analogue in the rational ethical sphere of the testing of Abraham.
} 
that front no gain has been made, since Kant rejects the argument from design, which would allow nature to be regarded as invested with God's rational will. ${ }^{9}$ This last crucial step is taken by allowing our reason to take its natural course (something which in the first Critique is shown to lead to illusion, but to which there can be no objection here, where reason is not pretending to be able to make constitutive pronouncements concerning the objects composing supersensible reality: it understands its business to be merely the satisfaction of its own needs). Reason reasons: If certain natural objects are conceived as realizing the concept of purpose, then we must (as in every field of rational knowledge) form the concept of a system of purposes, and systematicity demands a highest unifying point. For this we require something within nature which can be thought of as the final purpose of nature - and to that extent as something which is also outside nature. And the only candidate here is, of course, humanity - not as a bare natural species, homo sapiens, but as bearing its own purpose within itself, the unconditionally valuable good will, which cannot be a means to any further end. So we arrive by a long discursive route at the same point as the Critique of Aesthetic Judgement: a vision of Nature as our moral home.

What I have just given is, to repeat, only a very curtailed and selective sketch of the territory covered in the Third Critique, but it is enough to bring out the way in which the culminating point of both of its halves, the point where they converge, as distinct from merely exhibiting parallels, is provided by morality. To say this is not to say that there is nothing in Kant's aesthetic theory or his theory of teleology that can stand on its own two feet: the point is just that, to the extent that we have in view Kant's project of unification, the moral element is essential - it is what binds the parts of the text together. It follows that since - or to the extent that - we can no longer countenance according the same sort of philosophical authority to moral consciousness as Kant requires, the construal of the work as a would-be integral whole cannot grip us. ${ }^{10}$

\section{'Almost unfathomable insight': the German Idealist reception of the Third Critique I want to now talk about the early reception of the work. The motive here is not to turn away from philosophical to merely historical matters, but to use the history of philosophy as a way of approaching the Third Critique on something closer to its own terms. And the first, salient historical fact to fix on is that the CPJ exerted its greatest influence by a long chalk in the immediate Kantian aftermath, on the German Idealists, who regarded it as the most important of the three Critiques - not of course in a sense that would imply its independence from the others, but in so far as they took it to set the agenda for what philosophy after Kant should do, or put another way, which for them came to the same thing, what should be done with Kant's philosophy.}

Schelling and Hegel pay tribute to it in writings from early to late. Schelling's Of the I as Principle of Philosophy ranks the Critique of Teleological Judgment alongside the Transcendental Deduction of the first Critique:

\footnotetext{
${ }^{9}$ In a more profound sense than Hume. Kant's claim is not just that the inference to an Author of Nature is not inductively secure: it is that the concept of a natural end, which we apply to organisms, is distinct from that of an artefact.

${ }^{10}$ Even if the need for some sort of reassurance of morality's purposiveness is acknowledged, it will not be agreed that the $C P J$ 's transcendentalism is the right way to meet it. See Paul Abela, 'Kant, Naturalism, and the Reach of Practical Reason', in Sebastian Gardner and Mathew Grist (eds), The Transcendental Turn (Oxford: OUP, 2015), esp. 67-73.
} 
[W]hoever has read his deduction of the categories and his critique of the teleological power of judgment in the spirit in which everything he ever wrote must be read, sees the depth of his meaning and insight, which seems almost unfathomable [... Kant presented the ultimate substratum of all being and all identity] in a manner which appears possible only in a genius who, rushing ahead of himself, as it were, can descend the steps from the highest point, whereas others can ascend only step by step. $^{11}$

Schelling is of course implying that whoever has grasped this unfathomable depth of insight, will acknowledge that his own Fichtean Spinozism is present in Kant himself. Similarly, in his Munich lectures on the history of modern philosophy from the 1830s Schelling describes it as 'Kant's deepest work, which, if he could have begun with it as he finished with it, would have probably given his whole philosophy another direction'. ${ }^{12}$ Hegel's early Faith and Knowledge (1802) describes the critique of teleological judgement as 'the most interesting point of the Kantian system', ${ }^{13}$ and in the essay on ancient skepticism from the same year, he says that in the CPJ the mere 'philosophy of understanding' has been elevated above itself and displays the Idea of reason: 'The effective presence of this Idea is already visible in the outward scaffolding of its parts [of Kant's philosophy]; but it also emerges more explicitly at the culminating points of its syntheses, especially in the Critique of Judgement. ${ }^{14}$ In $\$ 55$ of the Encyclopaedia Logic (1817) Hegel again singles out the Third Critique as approximating more closely than anywhere else in Kant to the Idea, indeed as the only place in which 'the Kantian philosophy rises to the speculative height'.

The outstanding merit of the Critique of Judgement is that Kant has expressed in it the notion and even the thought of the Idea. The notion of an intuitive understanding, of inner purposiveness, etc., is the universal concurrently thought of as concrete in itself. It is only in these notions that Kant's philosophy shows itself to be speculative. ${ }^{15}$

In the late Lectures on the History of Philosophy Hegel again attributes its 'special importance' to the fact that it responds to a philosophical demand that Kant had failed to recognize in his previous works. ${ }^{16}$

\footnotetext{
${ }^{11}$ F. W. J. Schelling, Of the I as Principle of Philosophy, or On the Unconditional in Human Knowledge (1795), in The Unconditional in Human Knowledge: Four Early Essays 1794-1796, trans. and ed. Fritz Marti (Lewisburg: Bucknell University Press, 1980), 120n.

${ }^{12}$ F. W. J. Schelling, On the History of Modern Philosophy (1833-34/1836-37), ed. and trans. Andrew Bowie (Cambridge: CUP, 1994), 173.

${ }^{13}$ G. W. F. Hegel, Faith and Knowledge (1802), trans. Walter Cerf and H. S. Harris (Albany, NY: SUNY Press, 1977), 79.

${ }^{14}$ G. W. F. Hegel, 'On the Relationship of Skepticism to Philosophy' (1802), in George di Giovanni and H. S. Harris (eds), Between Kant and Hegel: Texts in the Development of Post-Kantian Idealism (Indianapolis: Hackett, 2000), 352.

${ }^{15}$ G. W. F. Hegel, The Encyclopaedia Logic (1817), trans. T. F. Geraets, W. A. Suchting and H. S. Harris (Indianapolis: Hackett, 1991). §55(c), 102.

${ }^{16}$ G. W. F. Hegel, Lectures on the History of Philosophy, Vol. 3: Medieval and Modern Philosophy, trans. E. S. Haldane and Frances H. Simson (Lincoln: University of Nebraska Press, 1995), 464: 'There is still left for us to consider the third side in Kant's philosophy, the Critique of the Faculty of Judgment, in which the demand for the concrete comes in, the demand that the Idea of unity spoken of before should be established not as a Beyond, but as present; and this side is of special importance.'
} 
It is worth noting, in connection with what I have said about the way in which the moral dependence of the Third Critique makes it alien to our concerns, that although the German Idealists did not accept Kant's accounts of moral knowledge, moral psychology, or human freedom, they were in no doubt (first) that Freedom represents the correct 'master concept' for general axiological purposes and (second) that the comprehensive task of philosophy must be defined at the outset in terms of the opposition of Freedom to Nature. (How that opposition is to be viewed at the end of the day - whether as a necessary starting point which has been overcome, or as sustained on some all-comprehending condition that explains its metaphysical necessity - is a separate matter.)

Now there are two questions concerning the German Idealists' reception of the Third Critique that I want to discuss. I said they took the CPJ to set an agenda, and as the quotations make very clear, not as saying the last word. So the question is: What in their eyes is wrong with or missing from the CPJ, such that it points up the need for further philosophical work? The second question follows on: If further work is needed, can it be done on the basis of anything contained within the $C P J$ itself?

We can begin to answer the first question by looking at the two major works in the postKantian period that constitute extended responses to the Third Critique, Schiller's Letters on Aesthetic Education (1794-95) and Herder's Kalligone (1800). Schiller is pro-Kant, with reservations, and Herder virulently anti-Kantian. But they agree on one thing: that human personality stands in need of a wholeness which is not on the cards if Freedom and Nature can only be unified only in the way and to the degree that the Critique of the Power of Judgement allows. Schiller argues accordingly that the aesthetic has the power to fuse Freedom and the Nature within us. His strategy is to use the intermediate position accorded by Kant to aesthetic judgement to, so to speak, 'get behind the back' of our theoretical and practical powers, in order to remould them: where Kant thinks of the aesthetic only as bridging theoretical and practical reason, a supervening late-comer that can react back on our theoretical and practical powers only in very limited ways, Schiller thinks of it as a superior standpoint with the power to condition them at their foundation. ${ }^{17}$ Herder's argument is that the gross inadequacies of Kant's aesthetics - its incongruity with the manifest character of the experience of beauty - are just what is to be expected from an intellectualist philosophy that splits reason from sense at root. ${ }^{18}$ For Herder, Kantianism is a lost cause - it cannot be enriched and repaired in the way Schiller proposes, and we must take a quite different approach; we must retrieve a rich, unitary concept of Nature which will avoid Kant's dualistic dead-end. Such an appreciation of Nature is exactly what Kant's merely subjective aesthetic of mental play stands in the way of, and Herder proceeds to give a painstaking account of how Kant has falsified aesthetic reality for the sake of scholastic philosophical abstractions. $^{19}$

Herder's Kalligone plays no direct role in the development of German Idealism, but the axiological sensibility to which it gives expression is entirely characteristic of the age, and

\footnotetext{
${ }^{17}$ See in particular Letters XVIII-XXII: On the Aesthetic Education of Man: In a Series of Letters (1793-95), trans. E. Wilkinson and L. Willoughby (Oxford: Clarendon, 1982), 122-159.

${ }^{18}$ See Herder's assault on the core claims of Kant's Analytic of the Beautiful in Part I, Ch. 5, of Kalligone (in Werke, ed. Günter Arnold et al, Vol. 8 of Schriften zu Literatur und Philosophie 1792-1800, ed. Hans Dietrich Irmscher (Frankfurt am Main: Deutscher Klassiker Verlag, 1998), 725-746).

${ }^{19}$ Herder's positive antagonism towards the $C P J$ reflects the thoroughly metaphysical character of his naturalism, and contrasts with the indifference to its concerns warranted by a purely scientific naturalism.
} 
Schiller may be viewed as laying down a first rough version of the German Idealist programme and as having projected the main lines of development that would carry postKantianism beyond Fichte's relatively conservative early reconstruction of the Critical philosophy.

The Third Critique was intended, among other things, as a criticism of the hyperbolic lifeexpectations of Sturm und Drang, as a vindication of the constraints of reason and a call for self-discipline. ${ }^{20}$ In the eyes of many of its contemporary readers, however, Kant's acknowledgement of the existence of a rift between Freedom and Nature merely highlighted a desideratum which the work could not itself satisfy, and the truly important question which it raised was whether Kant's admission of incompleteness, and his failure to repair it, amounted to the Critical system's self-condemnation or whether, as Schiller believed, the trajectory that Kant had begun to follow in the CPJ could be extended to a full solution.

Closely associated with this demand for theoretical and axiological wholeness in the human being was the complaint that Kant fails in the CPJ to satisfy his own formal conditions for philosophical finality. In Fichte's late lectures we find a precise formulation of this objection:

The way his decisive and only truly meaningful works, the three critiques, come before us, Kant has made three starts. In the Critique of Pure Reason, his absolute $(\mathrm{x})$ is sensible experience [... In the Critique of Practical Reason] we get the second absolute, a moral world $=\mathrm{z}$ [... With the] introduction of the moral world as the one world in itself, the empirical world is lost, as revenge for the fact that the latter had initially excluded the moral world. And so the Critique of the Power of Judgement appears, and in its Introduction, the most important part of this very important book, we find the confession that the sensible and supersensible worlds must come together in a common but wholly unknown root, which would be the third absolute = y. I say a third absolute, separate from the other two and self-sufficient, despite the fact that it is supposed to be the connection of both other terms; and I do not thereby treat Kant unjustly. Because if this $y$ is inscrutable [unerforschlich], then while it may indeed always contain the connection, I at least can neither comprehend it as such, nor collaterally conceive the two terms as originating from it [ich wenigstens kann es als solchen nicht durchdringen, und die beiden Nebenglieder, als aus inm hervorgehend, nicht mittelbar begreifen]. If I am to grasp it, I must grasp it immediately as absolute, and I remain trapped forever, now as before, in the (for me and my understanding) three absolutes. Therefore, with this final decisive addition to his system, Kant did not in any way improve that which we owe to him, he only generously admitted and disclosed it himself. ${ }^{21}$

Fichte concludes: Kant first 'factically discovered the distinction between the sensible and supersensible worlds and then added to his absolute the additional inexplicable quality of linking the two worlds'. ${ }^{22}$

\footnotetext{
${ }^{20}$ See John Zammito, The Genesis of Kant's Critique of Judgment (Chicago: University of Chicago Press, 1992).

${ }^{21}$ J. G. Fichte, The Science of Knowing: J. G. Fichte's 1804 Lectures on the Wissenschaftslehre, trans. Wayne Wright (Albany, NY: SUNY Press, 2005), 31-32.

${ }^{22}$ Ibid, 44.
} 
Now this passage is highly revealing of what is at issue in the argument between Kant and his successors, and it repays close attention. Fichte assumes three things: that each of Kant's Critiques must be taken as presenting an 'absolute'; that whatever is posited as absolute must be 'grasped', indeed 'grasped immediately'; and that Kant's invocation of a third term, ' $y$ ', to connect Freedom and Nature, fails because $y$, as theorized by Kant, is not equipped to be their 'root' and provide their 'origin'.

The first two will be unhesitatingly rejected by Kant, who will retort that Critical philosophy is not in the business of grasping absolutes. The third however is not so easily dismissed. Even if Fichte is too quick to assert that 'y' needs to be grasped as an absolute, he is right that it needs to have some independent identity if it is to be effective in its connecting role, and that if this role is to be fulfilled rationally then its occupant must show the intelligibility of the connection; if it does not - if ' $y$ ' is inscrutable, if it cannot be comprehended in its role then it means nothing to assert that it 'contains' the connection of $x$ and $z$. Now Kant may reply that all of this work is indeed done in the $C P J$, which provides an account of what judgement amounts to as a power of its own, with a principle of its own, and of how the world may be conceived as an interconnected domain of Freedom and Nature, namely as a system of purposes. Yet Fichte can still reasonably object that interposing $y$, even if it displays thematic continuity with $x$ and $z$, fails to improve our situation: if our knowledge of $y$ is on a level with our knowledge of $x$ and $z$ - if $y$ is similarly un-self-grounding - then we have merely added complexity, for we now need to understand how all three hold themselves together. Fichte's point is therefore that postulating $y$ would bring a gain only if it stood behind Freedom and Nature, grounding them at a deeper level - which is certainly not what Kant is either prepared or able to claim regarding judgement, taste, and teleological judgement of nature. Even if the concept of purposiveness is shown in the CPJ to stand in some sense at the summit of our cognition, ${ }^{23}$ the way that it comes to be established in that position - namely as an afterthought, once the theories of theoretical and practical cognition have been completed - means that it lacks both (i) the epistemic primitiveness and selfsufficiency, and (ii) the capacity to generate the terms subordinate to it, required for the Kantian 'system' to count as anything more than a patchwork. Kant may have shown that $y$ is continuous with $x$ and $z$ but not that it is their 'root' and 'origin'.

In the background to Fichte's complaint is the notorious 'single first principle' issue that dominated discussion of Kant's epistemology in the first phase of its reception, centred on the contention that the Kantian system's lack of such a principle rendered it vulnerable to skeptical attack and incapable of meeting the skeptical challenge to human knowledge in general. The two debates are not straightforwardly the same, because in the present context we are not concerned with finding a principle that will resist skeptical doubt, but nor are they dissociated. ${ }^{24}$ And in both contexts Kant appears to have contributed to the difficulty in which he finds himself by virtue of a claim that he makes in the first Critique concerning the meaning of systematicity:

\footnotetext{
${ }^{23}$ The 'highest formal unity that alone rests on concepts of reason is the purposive unity of things' (CPR, A686/B714).

${ }^{24}$ That Fichte does not, in the passage quoted, invoke the threat of skepticism, does not mean that he regards the issues as properly separate. See Paul Franks' magisterial account in All or Nothing: Systematicity, Transcendental Arguments, and Skepticism in German Idealism (Cambridge, MA: Harvard University Press, 2005).
} 
If we survey the cognitions of our understanding in their entire range, then we find that what reason quite uniquely prescribes and seeks to bring concerning it is the systematic in cognition, i.e., its interconnection based on one principle [Zusammenhang aus einem Princip]. This unity of reason always presupposes an idea, namely of the form of a whole of cognition, which precedes the determinate cognition of the parts and contains the conditions for determining a priori the place of each part and its relation to the others. Accordingly, this idea postulates complete unity of the understanding's cognition, through which this cognition comes to be not merely a contingent aggregate but a system interconnected in accordance with necessary laws. One cannot properly say that this idea is the concept of an object, but only that of the thoroughgoing unity of these concepts, insofar as the idea serves the understanding as a rule. ${ }^{25}$

If Kant is held to this statement, then the expectation of finding in the CPJ a grounding, superordinate principle may seem reasonable, and Fichte's disappointment with Kant justified. And yet, if this is so, then it is puzzling that Kant failed to see the problem. It is true that he spells out in the Introduction a principle, the a priori principle of judgement concerning nature's purposiveness, ${ }^{26}$ which might in a thin and somewhat forced sense be said to overarch Freedom and Nature, but it is not a source of 'necessary laws' for either, and this can hardly have escaped Kant's notice. This should lead us to ask if the Third Critique is perhaps aiming to satisfy the conception of systematicity laid down in the Critique of Pure Reason in some less direct, more oblique and qualified way.

As every reader discovers, the cumulative effect of the text of the CPJ is that of a kind of echo chamber, in which structures on one side of a distinction are found to reappear, in inverted form, on the other, setting up a complex system of internal correspondences. These correspondences are not inferential relations or relations of explanation, at any rate not in the first instance. At the same time, the text gives an impression of conceptual movement, of pieces drawing together and converging on unity, but because this final point is never achieved, the movement is never completed; and because what sets them in motion is not force of deduction but elective affinity, the movement has a spontaneous character, as if the various domains were arranging themselves of their own accord and yet at the same time in accordance with reason. ${ }^{27}$ Here is an example, from Section VIII of the Introduction:

In an object given in experience purposiveness can be represented either on a merely subjective ground, as a correspondence of its form in its apprehension (apprehensio) prior to any concept with the faculties of cognition, in order to unite the intuition with concepts for a cognition in general, or on an objective ground, as a correspondence of its form with the possibility of the thing itself, in accordance with a concept of it which precedes and contains the ground of this form. We have seen that the representation of the first sort of purposiveness rests on the immediate pleasure in the form of the object in mere reflection on it; thus the representation of the second kind of purposiveness, since it relates the form of the object not to the cognitive

\footnotetext{
${ }^{25} \mathrm{~A} 645 / \mathrm{B} 673$.

${ }^{26}$ CPJ, Introduction, Sect. IV, 5:180-181.

${ }^{27}$ Explicitly dynamic images of systematicity are associated with, on the one hand, the task of infinite approximation of the German Romantics, and on the other, Hegel's Concept. My suggestion is that the image is also to be found implicit in Kant.
} 
faculties of the subject in the apprehension of it but to a determinate cognition of the object under a given concept, has nothing to do with a feeling of pleasure in things but rather with the understanding in judging them. ${ }^{28}$

Here Kant is spelling out the kinship and differentiation of aesthetics and the teleology. Both involve representing an object as purposive, the former on a subjective, the latter on an objective ground. The subjective ground is a correspondence of the form of the object with the faculties of cognition, established independently of any concept. The objective ground is a correspondence of the form of the object with the concept that provides its ground. The former involves form as apprehended, the latter form as conceptualized. So the former manifests itself sensibly in feeling, the latter intellectually in a judgement of the understanding; - though the terms of that distinction too are mutually implicating, since the feeling which is distinctive of aesthetic experience rests on an activity of judgement, and it is only because the mind has a 'feel for' purposive form, as taste shows, that nature can be taken up teleologically. Aesthetics and teleology are therefore each the inversion of the other. Taste feels the purposivity which teleology thinks. Teleology refers to the object's own possibility; taste indexes the possibility of its figuring as an object for us.

Numerous other passages of this sort, where architectonic pressures drive the argument, may be cited. ${ }^{29}$ Kant has been derided for his obsession with architectonic, but it can hardly be doubted that he regards it as a serious matter. The reason for its prominence in the CPJ, which is greater than elsewhere, is that there Kant is elevating it from being merely the means by which one eventually arrives at a system - 'art' in the sense of techne, production of an object - to being what constitutes systematicity. This does not mean Kant has abandoned the conception of philosophical systematicity described in the Critique of Pure Reason and to which Fichte appeals in his criticism of the CPJ. For Kant the bare idea of a philosophical system is simple enough, and adequately expressed by the 'one principle' formula, but this is only because it is indeterminate, and it is only when it has been made determinate that we can be said to know what philosophical systematicity consists in; and because rendering it determinate is a matter of knowing how it is to be realized, architectonic is constitutive of systematicity. ${ }^{30}$ Within the sub-systems which form the parts of the system of philosophy, the foundations of empirical knowledge and the metaphysics of morals, the search for 'interconnection based on one principle' has a straightforward methodological significance, leading to the principles of apperception and autonomy, but in application to the system of philosophy as a whole, in the singular context of unifying Nature and Freedom, it must be understood as requiring something different, namely an exposition of the interrelatedness of its sub-systems and the thematic unity of those unifying relations. This

\footnotetext{
${ }^{28}$ CPJ, Introduction, Sect. VIII, 5:192.

${ }^{29}$ For example, Kant's interweaving of purposiveness and aesthetic pleasure in Section VII of the Introduction, 5:188-192, or the argument in Section II of the First Introduction, 20:201-205, that, since judgement is a faculty of cognition located between understanding and reason, and these have their a priori principles, judgement too should be thought to have one.

${ }^{30}$ The first paragraph of the original (First) Introduction to the $C P J$ explains that philosophy as 'the system of rational cognition through concepts' is to be approached via the critique of pure reason, which 'outlines and examines the very idea of it in the first place' - implying that it is for critique to determine to what extent, and in what form, the idea of a philosophical system can be realized (CPJ, 20:195; see also CPR, A13/B27). In the $C P R$ Kant asserts that for its execution (realization: Ausfuihrung) the idea 'needs a schema' incoroporating a manifold (A833/B861), and that architectonic must begin 'only at the point where the general root of our cognitive power divides' into the rational and empirical.
} 
exposition of course involves, but it also goes beyond, logical connection in a strict deductive sense, and the extra-logical formal affinities and structural correspondences of sub-systems are philosophically probative, for the fact that the results of philosophical enquiry in different domains display common patterns, appearing as variations on a theme (namely purposiveness), assures us that we have got things right, and allows us to regard the system we construct as holding itself up from the inside. ${ }^{31}$

This might seem to imply that Kant is offering a quasi-aesthetic satisfaction, architectonic harmony, in place of philosophical understanding, running him implausibly close to the Frühromantiker. But in fact we can understand how the architectonic conception of systematicity serves strictly philosophical purposes, and even that Kant has an argument for why it is the only kind of philosophical systematicity available to the human intellect.

Going back to the original paragraph affirming the 'incalculable gulf' between Freedom and Nature, we should note that Kant confines the aim of the task of unification to facilitating the transition from the one to the other (thinking in accordance with the principles of the one to those of the other). This is something different from cognizing their connection and it shows immediately how far he is from sharing Fichte's view of the problem. Also notable is that Kant talks in one breath of facilitating the transition, and of positing an object that would rationalize it, suggesting he regards the distinction that we ordinarily draw between cognizing an object, and being able to do something, as a vanishing distinction in the rarefied context at hand. Exactly the same is signalled in the passage from the first Critique where Kant said that the idea which 'postulates complete unity of the understanding's cognition' cannot properly be said to be 'the concept of an object' but rather 'serves the understanding as a rule'.

This notion - that at the outer limit of transcendental reflection ideas of the supersensible are equivalent to rules for transitions between domains of cognition or sub-systems of philosophy - is one that evidently appealed to certain philosophers in Kant's wake, such as Peirce, who were interested in a basal fusion of theory and practice and proposed that concepts in general be regarded as specifying procedures and modes of operation. That Kant himself is so far advanced in pragmatism as to recommend a reduction of this sort may be doubted, and if we look further into the $C P J$ we can understand how he manages to keep objective reference in play alongside his conception of ideas as having essentially regulative significance, and without admitting knowledge of the noumenal.

The other suggestion I made was that Kant can rationalize his conception of systematicity by referring to the distinctive character of the human intellect. In two remarkable sections of the Dialectic of Teleological Judgement, $\S \S 76-77,{ }^{32}$ Kant describes the differences between our discursive mode of cognition, and another, non-discursive mode of cognition which we cannot know to exist, but of which we can at least form a concept, and which he calls an intuitive intellect. In $\S 77$ he explains that the non-discursive cognition of this intuitive intellect would proceed from the universal to the particular:

\footnotetext{
${ }^{31}$ See $C P J, \S 68,5: 381$ : 'Every science is of itself a system; and it is not enough that in it we build in accordance with principles and thus proceed technically; rather, in it, as a freestanding building, we must also work architectonically, and treat it not like an addition and as a part of another building, but as a whole by itself, although afterwards we can construct a transition from this building to the other or vice versa.'

${ }^{32}$ Picked out by Hegel in the earlier quotation as approximating to 'the Idea'.
} 
[W]e can also conceive of an understanding which, since it is not discursive like ours but is intuitive, goes from the synthetically universal (of the intuition of a whole as such) to the particular, i.e., from the whole to the parts. ${ }^{33}$

Human cognition is not like this: our a priori concepts do not contain knowledge of any particulars (they are not intuitions), and all of our determinate concepts of really existing things have to be built up out of sensible intuitions of particulars. God's knowledge may be top-down, but ours is bottom-up:

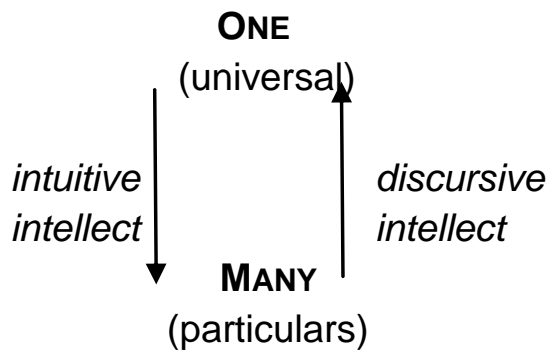

That is why we need reflective judgement: it provides the ladder allowing us to climb up from the Many to the One. ${ }^{34}$

When all of this is appreciated - when we see that our cognition travels logically in the opposite direction from that of an intuitive intellect - it becomes clear that the conception of final philosophical systematicity as knowledge of a whole out of which its parts can be determined, cannot in principle be satisfied. At the very point where we would achieve knowledge of this whole, our mode of cognition would cease to be discursive, and we as knowers would be extinguished. What we may think nevertheless is that this idea of a prior whole, though unrealizable by our cognition, has regulative value, in so far as it furnishes an imaginary focal point towards which we steer our cognition. And so long as we appreciate that its status is merely regulative, we avoid transcendental illusion. What may also be claimed, compensating for the lesson in humility, is that we can regard our discursive representation, as it gains in systematicity, as tracking the reality given to an intuitive intellect: $^{35}$ our progress towards an ever more determinate, tightly coherent conceptualization of appearance is a continual approximation, within the idiom of human cognition, to the things in themselves which are present to God's creative intellect. ${ }^{36}$ The

\footnotetext{
${ }^{33}$ CPJ, §77, 5:407.

${ }^{34}$ And more specifically why we need teleological judgement. See the conclusion of $\$ 70,5: 388$, which explains how teleological judgement makes up for our ignorance of a 'single principle'. Discussion of the single principle issue is resumed in $§ 78$ : 'it follows that the unification of the two principles cannot rest on a ground for the explanation (explication) of the possibility of a product in accordance with given laws for the determining power of judgment, but only on a ground for the elucidation (exposition) of this for the reflecting power of judgment. - For to explain means to derive from a principle, which one must therefore cognize distinctly and be able to provide' (5:412).

${ }^{35}$ This move involves a further element, not yet mentioned: Kant argues in $C P J, \S 76,5: 403-404$, that what has the value of Seyn-Sollen for the human intellect, what should be the case, has being, Seyn, for the intuitive intellect. More detailed discussion of the themes in this section may be found in my 'German Idealism, Classical Pragmatism, and Kant's Third Critique', in Gabriele Gava and Robert Stern (eds), Pragmatism, Kant, and Transcendental Philosophy (London: Routledge, 2016).

${ }^{36}$ The image needed here is complex but coherent: human cognition and the intuitive intellect comprise two heterogeneous non-intersecting dimensions, but as we move in a certain direction along the one that is ours, the
} 
cognitive maximum possible for human cognition according to Kant has therefore two aspects. On the one hand it presupposes what Kant calls, in his discussion of freedom in the Groundwork, a comprehension of incomprehensibility, the sphere of the incomprehensible being the domain of the intuitive intellect as cognized by the intuitive intellect. This absolute limitation is reflected in the necessity of our employing concepts that, the critique of reason shows, cannot be taken to determine any object and can serve only as formal rules. But at the same time, the projected totality of human cognition available in principle at the end of enquiry may be regarded as an indirect presentation of the intuitive intellect's whole of reality. The concept of such an oblique, analogical cognition is developed within the CPJ, under the heading of symbolic presentation, symbolische Darstellung, the type of relation which holds between the beautiful and the morally Good. ${ }^{37}$ The conclusion to which discussion of Fichte's complaint leads is therefore that Kant does indeed fail to supply a single principle from which the parts of the system of philosophy might be derived, but that this seeming shortfall is rationalized by $\S \S 76-77$, which also explains why the concept of purpose should emerge as the key to the unification of Freedom and Nature: it stands in for the 'synthetically universal' intuition of a whole available to the intuitive but not the human intellect. In a sense, then, though not one that Fichte will accept, the 'absolute' that he finds missing from the CPJ can after all be found in it: it is present in a negative form, as the account of human cognition given in $\S \S 76-77$.

Kant's exposition of the idea of an intuitive intellect in $\S 77$ leads directly to the other question I raised, concerning the extent to which the Third Critique may provide resources for the more ambitious philosophical task which the German Idealists took it to set (and thereby promote its own surpassing).

Fichte did not consider it to do so. Fichte returns to the themes of the first two Critiques - the self and moral consciousness - in order to close the gap between Freedom and Nature. But the crucial, decisive move to the more radical form of post-Kantianism, absolute idealism, taken by Schelling, does draw on the CPJ. One should hesitate before saying that Schelling's absolute idealism strictly depends on his critical appropriation of the CPJ, because there are so many forces at work in Schelling, but it is certainly one major element.

Schelling's claim is that Kant has in the CPJ all of the materials required to take the step to a stronger form of idealism, and that it is arbitrary to hold back. His argument is best seen by looking at a passage (from the First Introduction) which allows us to pinpoint where, as Schelling sees it, Kant's idealism properly passes over into his own idealistic Spinozism: ${ }^{38}$

Now it is clear that the reflecting power of judgment, given its nature, could not undertake to classify the whole of nature according to its empirical differences if it did not presuppose that nature itself specifies its transcendental laws [die Natur spezifiziere selbst ihre transzendentale Gesetze] in accordance with some sort of principle. Now this principle can be none other than that of the suitability for the

content of our cognition, the order of objects that it represents, becomes increasingly isomorphic with that of the intuitive intellect.

${ }^{37}$ CPJ, $\$ 59,351-352$.

${ }^{38}$ To be clear, Schelling does not discuss this passage: I am extrapolating from what he does say about Kant's teleology in the Introduction to his Ideas for a Philosophy of Nature (1797, 2nd \& revised edn. 1803), trans. Errol E. Harris and Peter Heath (Cambridge: CUP, 1988), 30-42. 
capacity of the power of judgment itself for finding in the immeasurable multiplicity of things in accordance with possible empirical laws sufficient kinship among them to enable them to be brought under empirical concepts (classes) and these in turn under more general laws (higher genera) and thus for an empirical system of nature to be reached [...] The special principle of the power of judgment is thus: Nature specifies its general laws into empirical ones, in accordance with the form of a logical system, in behalf of the power of judgment [Das eigentümliche Prinzip der Urteilskraft ist also: die Natur spezifiziert ihre allgemeine Gesetze zu empirischen, gemäß der Form eines logischen Systems, zum Behuf der Urteilskraft.]. ${ }^{39}$

Here Kant is arguing - and this is yet another piece in his puzzle, not yet mentioned - that in order for us to be able to form empirical concepts at all, experience needs to exhibit the type of regularity that will allow us to formulate concepts of natural kinds and laws of nature. This regularity cannot be proven, or its ground known; so all that can be done is to assume, as a subjective and merely regulative matter, that (as Kant puts it) nature 'specifies itself' in accordance with the principle that it is to be possible for us to have knowledge of it. In ignorance of what may in fact determine nature's self-specification, we project this principle 'up' the order of cognition, as it were demanding of the intuitive intellect that it produce objects in accordance with our cognition.

Schelling regards Kant's reasoning to the conclusion that nature must specify itself as sound, but his subjective construal of the conclusion as incoherent. If we must (as a matter of transcendental necessity) think of nature as self-specifying, rather than simply as subject to our legislation (as throughout the first Critique), then we cannot, having granted it this autonomy, take it away again by identifying its principle with a mere subjective necessity of ours. In attempting to save his Copernican principle that our mode of cognition must be ultimately determining of its objects, Kant takes back with one hand what he gives by the other: he cancels his own insight that by consistently following through the Copernican programme we are brought to a point where subjective idealism must yield to realism, or rather, to objective idealism. When this is recognized, what comes into view is Schelling's Spinozistic view of Nature:

As long as we only know the totality of objects as the sum total of all being, this totality is a mere world, that is, a mere product for us [...] Insofar as we regard the totality of objects not merely as a product, but at the same time necessarily as productive, it becomes Nature for us, and this identity of the product and the productivity, and this alone, is implied by the idea of Nature, even in the ordinary use of language. Nature as a mere product (natura naturata) we call Nature as object (with this alone all empiricism deals). Nature as productivity (natura naturans) we call Nature as subject (with this alone all theory deals). ${ }^{40}$

\footnotetext{
${ }^{39}$ CPJ, First Introduction, Sect. V; 20:215-216.

${ }^{40}$ Schelling, Introduction to the Outline of a System of the Philosophy of Nature (1799), §6, in First Outline of a System of the Philosophy of Nature (1799), trans. Keith R. Peterson (Albany, NY: SUNY Press, 2004), 202.
} 
The 'theory' referred to here is Schelling's Naturphilosophie or 'speculative physics', which views nature in its productivity as an organic whole, reducing the difference of organic and inorganic nature to a relative distinction within nature qua product. ${ }^{41}$

Now one might accept that the CPJ creates space for absolute idealism, while also thinking that more reassurance is needed before it would make sense to embrace it. So is there any reason for thinking that this move is compelled? Here we can go back to Fichte's criticism and state his point in a slightly different way. Kant is committed, we have seen, to multiple worlds or sub-systems of rational cognition, the inter-relations of which are to be elucidated from within the standpoint of each, without stepping outside them. (So we try to work out, from within Nature and within Freedom, how the gulf between them might be bridged.) This part-to-whole model fits empirical knowledge and it is what Kant's conception of the human intellect implies. But even if Kant can show the sub-systems to be not only consistent with one another but also convergent in the way his architectonic claims, what his multi-systemic model omits and cannot account for, arguably, is the antecedently given transcendental, meta-fact of our contemporaneous occupation of multiple worlds or sub-systems - the fact, which announces itself when we find it puzzling that we are able to move from the one to the other, that at the very outset we can take ourselves to occupy multiple domains. If this problem is to have a solution, so it may be argued, then Kant's commitment to confining philosophical reason within the perspectives of each world or sub-system must be surrendered, and this means laying claim, as absolute idealism does, to the perspective of the whole.

Whether absolute idealism fulfills its promise to preserve Kant's differentiation of reason into its specific forms, while holding them in unity, is, of course, another story. What I have tried to do is just to give a glimpse into the perspective from which the Third Critique displays, as Schelling put it, a 'depth of meaning and insight which seems almost unfathomable'.

SEBASTIAN GARDNER (sebastian.gardner@ucl.ac.uk) is Professor of Philosophy at University College London. His recent publications include The Transcendental Turn, coedited with Matthew Grist (Oxford University Press, 2015), and articles on classical German philosophy.

\footnotetext{
${ }^{41}$ Ibid, 227, 232.
} 